Doctrina

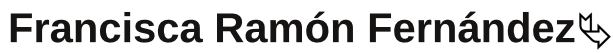

\section{Seguridad y responsabilidad de los productos cosméticos en el Derecho Español}

\section{Safety and Responsibility of Cosmetic Products in Spanish Law}

Segurança e responsabilidade de produtos cosméticos no Direito Espanhol

Agradecimientos: Trabajo realizado en el marco del Proyecto $I+D+i$ «Retos investigación» del Programa estatal de I+D+i orientado a los Retos de la Sociedad del Ministerio de Ciencia, Innovación y Universidades: RTI2018-097354-B-100. «Contratos, transparencia y protección de datos en el mercado digital» (2019-2022). Investigadores Principales: Dr. Javier Plaza Penadés, Catedrático de Derecho Civil, y Dra. Luz M. Martínez Velencoso, Catedrática de Derecho Civil. Universitat de València-Estudi General.

Resumen: A propósito del Real Decreto (RD) 85/2018, del 23 de febrero, por el que se regulan los productos cosméticos en el Derecho Español vamos a reflexionar sobre la seguridad y protección del consumidor. Nos interesa determinar si la regulación existente es conforme a la cosmetovigilancia para lograr que estos productos sean seguros y determinar el ámbito de responsabilidad en caso contrario.

Palabras Clave: cosmético, seguridad, consumidor, salud, protección, legislación, producto defectuoso.

Abstract: About the Royal Decree (RD) 85/2018, of February 23, by which the cosmetic products are regulated in Spanish Law we are going to think about the safety and protection of the consumer. We are interested in determining if the existing regulation is in conformity with the ecosmetics monitoring department to achieve that these products are sure and to determine the area of responsibility in opposite case.

\footnotetext{
$\stackrel{\rightarrow}{\rightarrow}$ Profesora titular de Derecho Civil. Universitat Politècnica de València (España). ORCID: 00000002-0936-8229

$\triangle$ frarafer@urb.upv.es
} 
Keywords: Cosmetic, Safety, Consume, Health, Protection, Legislation, Defective Product.

Resumo: Com relação ao Decreto Real $(R D)$ 85/2018, de 23 de fevereiro, que regulamenta os produtos cosméticos no Direito Espanhol, refletiremos sobre a segurança e proteção do consumidor. Estamos interessados em determinar se a regulamentação existente está de acordo com a cosmetovigilância para garantir que esses produtos sejam seguros $e$ determinar o escopo de responsabilidade de outra forma.

Palavras-chave: cosmético, segurança, consumidor, saúde, proteção, legislação, produto defeituoso.

Recibido: 20190425

Aceptado: 20190605 


\section{Introducción}

En el ámbito del consumo, los productos cosméticos gozan de una gran aceptación por sus propiedades o características que hace que el público destinatario sea muy amplio (Garrigues, 2018). Los consumidores de estos productos buscan principalmente el embellecimiento o el tratamiento para paliar determinadas afecciones, ya que no podemos olvidar que estos productos, en ocasiones, tienen en su composición un principio activo destinado a retrasar el envejecimiento, proteger contra radiaciones solares, entre otros usos. Se crean también como híbrido entre cosmético y producto farmacéutico, los denominados "cosmeceúticos" que operan en los límites de la legalidad, ya que los cosméticos tienen una regulación más laxa que los productos farmacéuticos (Fernández, Fresno y Sellés, 1995), sujetos a ensayos clínicos y control de calidad más exhaustivo (López, 2016, 43).

De esta forma, la farmacología en España es muy estricta respecto a la introducción de medicamentos, así como su uso como tales, destacando la siguiente legislación que no se aplica, en ningún caso, a los cosméticos. Así, cabe citar la Ley 10/2013, de 24 de julio, por la que se incorporan al ordenamiento jurídico español las Directivas 2010/84/UE del Parlamento Europeo y del Consejo, de 15 de diciembre de 2010, sobre farmacovigilancia, y 2011/62/UE del Parlamento Europeo y del Consejo, de 8 de junio de 2011, sobre prevención de la entrada de medicamentos falsificados en la cadena de suministro legal, y se modifica la Ley 29/2006, de 26 de julio, de garantías y uso racional de los medicamentos y productos sanitarios (BOE, Boletín Oficial del Estado, núm. 177, de 25 de julio de 2013).

Y resulta precisamente de interés la normativa en materia de consumidores y usuarios representada por el Real Decreto Legislativo 1/2007, de 16 de noviembre, por el que se aprueba el texto refundido de la Ley General para la Defensa de los Consumidores y Usuarios y otras leyes complementarias (en adelante, RDL 1/2007) (BOE núm. 287, del 30 de noviembre de 2007). Esta norma ha sido objeto de reforma en diversas ocasiones (ver anexo 1 ). 
De especial interés resulta mencionar la modificación operada por Ley 3/2014, del 27 de marzo (BOE núm. 76, de 28 de marzo de 2014), por afectar a los mecanismos de protección para la seguridad de los consumidores y productos, siendo precisamente uno de los objetivos, la seguridad (Hernández, 2013). Entendida también ésta que el producto haya sido elaborado cumpliendo unos requisitos adecuados para que pueda ser posteriormente comercializado (Martín, 1998).

En el ámbito europeo, el Reglamento (CE) núm. 1223/2009, del Parlamento Europeo y del Consejo, del 30 de noviembre de 2009, sobre los productos cosméticos (OJ L 342, del 22 de diciembre de 2009), (en adelante, Reglamento (CE) núm. 1223/2009) que se aplica desde el 11 de julio de 2013 (Prats, 2013; Ruiz, 2015), indica que los productos cosméticos tienen que ser seguros en las condiciones de utilización normales o razonablemente previsibles, y observar las normas referentes a la composición y etiquetado. Se establecen unas obligaciones para los sujetos implicados, como la notificación de efectos graves no deseados, y disponer de un informe de seguridad, así como garantizar la trazabilidad dentro de la cadena de producción. En definitiva, privilegia el buen funcionamiento del mercado para lograr un alto nivel de protección de la salud y con el fin garantista de evitar la utilización de animales en la experimentación de los productos.

Como precisa Hernández $(2013,4)$ se trata de un sector ampliamente regulado —el cosmético-, y el Reglamento (CE) núm. 1223/2009 armoniza las normas comunitarias, y persigue las siguientes finalidades: imposición de normas claras y detalladas; se garantiza que todos los requisitos legales se apliquen simultáneamente en toda la UE; simplificación de procedimientos y racionalización de la terminología; refuerzo de elementos dentro del marco regulatorio del producto cosmético; determinación de las responsabilidades en la cadena de suministros y garantizar la eficacia de las medidas contra la falsificación; inclusión de normas relativas a la calidad y seguridad, información al consumidor y prohibición de experimentación en animales.

Esta norma ha sufrido distintas modificaciones (ver anexo 2).

A pesar de que el Reglamento comunitario es directamente aplicable, ha sido preciso una regulación estatal individualizada para los aspectos que se deja por parte de la Unión Europea a los Estados miembros, como ha señalado el Real Decreto 85/2018, del 23 de febrero, por el que se regulan los productos cosméticos BOE núm. 51, del 27 de febrero de 2018. (en adelante, RD 85/2018). 
Esta nueva normativa determina la regulación de algunos aspectos, como precisa el artículo 1 del RD 85/2018) que vamos a tratar en el presente trabajo:

Primero, autoridades competentes para la supervisión del mercado y para la recepción y transmisión sobre los efectos graves y no deseados para la salud, y el sistema español de cosmetovigilancia, para recoger y evaluar la información sobre los efectos indicados.

Segundo, la adopción de medidas de protección para la salud, y la constitución de la red de alerta nacional de productos cosméticos.

Tercero, indicaciones respecto al etiquetado de los productos.

Indicar que la normativa que afecta al tema objeto de nuestro estudio, en el ámbito de la legislación española y europea es muy extensa, por lo que en ningún caso el trabajo agota la referencia a la misma, y no supone un análisis totalmente exhaustivo, por exceder los límites del presente estudio. No obstante, se recogen las principales normas que, de forma directa o indirecta, afectan al ámbito tratado.

\section{El Real Decreto 85/2018, de 23 de febrero, por el que se regulan los productos cosméticos}

El RD 85/2018 deroga el Real Decreto 1599/1997, de 17 de octubre, sobre productos cosméticos (BOE núm. 261, de 31 de octubre de 1997) excepto y hasta que se regulen de forma específica los productos de cuidado personal, se seguirá aplicando los artículos 4, 12, 13, 15 y 16, y el capítulo VII del Real Decreto 1599/1997, de 17 de octubre, siempre que resulte compatible con lo que se indica en el régimen de declaración responsable al que se sujeta la actividad de fabricación e importación de estos productos, según indica la disposición adicional tercera del Real Decreto Legislativo 1/2015, del 24 de julio, por el que se aprueba el texto refundido de la Ley de garantías y uso racional de los medicamentos y productos sanitarios (en adelante, RDL 1/2015) (BOE núm. 177, de 25 de julio de 2015).

También queda derogado el Real Decreto 209/2005, del 25 de febrero, por el que se modifica el Real Decreto 1599/1997, del 17 de octubre, sobre productos cosméticos (BOE núm. 49, de 26 de febrero de 2005). A su vez el RD 1599/1997 había derogado anteriormente la normativa siguiente: Real Decreto 349/1988, del 15 de abril, por el que se aprueba la Reglamentación Técnico-Sanitaria de produc- 
tos cosméticos (BOE núm. 95, de 20 de abril de 1988) y Real Decreto 475/1991, del 5 de abril, por el que se modifica la Reglamentación Técnico-Sanitaria de Productos Cosméticos, aprobada por el Real Decreto 349/1988, de 15 de abril (BOE núm. 86, de 10 de abril de 1991).

Como indica el Reglamento (CE) núm. 1223/2009 en el considerando 7, para determinar si un producto es o no cosmético «ha de efectuarse un análisis caso por caso, teniendo en cuenta todas las características del producto». Distingue entre distintos tipos de productos cosméticos, tanto en el ámbito de la higiene, como maquillaje, productos para el baño, y para el tratamiento del cabello, y el peinado, así como para el afeitado, y desmaquillantes, junto con productos aplicables para el cuidado bucal, uñas, higiene íntima, solares, y antiarrugas.

Es por ello, que en el artículo 2 del citado texto legal, tal y como se remite el artículo 2 RD 85/2018, se considera como producto cosmético «toda sustancia o mezcla destinada a ser puesta en contacto con las partes superficiales del cuerpo humano (epidermis, sistema piloso y capilar, uñas, labios y órganos genitales externos) o con los dientes y las mucosas bucales, con el fin exclusivo o principal de limpiarlos, perfumarlos, modificar su aspecto, protegerlos, mantenerlos en buen estado o corregir los olores corporales».

Como vemos, no hace mención a ningún tipo de uso de carácter médico o farmacéutico, ni a la composición con fórmulas que contengan vitaminas, aunque cuando hace mención al término sustancia indica que se trata de «un elemento químico y sus compuestos naturales o los obtenidos mediante algún proceso industrial, incluidos los aditivos necesarios para conservar su estabilidad y las impurezas que inevitablemente se produzcan en el proceso, con exclusión de todos los disolventes que puedan separarse sin afectar a la estabilidad de la sustancia ni modificar su composición».

Sin embargo, se considera aplicable a los cosméticos la regulación que establece el RDL 1/2015, según indica el artículo 1, y el artículo 2, n) define el producto cosmético como «Toda sustancia o mezcla destinada a ser puesta en contacto con las partes superficiales del cuerpo humano (epidermis, sistema piloso y capilar, uñas, labios y órganos genitales externos) o con los dientes y las mucosas bucales, con el fin exclusivo o principal de limpiarlos, perfumarlos, modificar su aspecto, protegerlos, mantenerlos en buen estado o corregir los olores corporales». 
Según indica el artículo 3 será la Agencia Española de Medicamentos y Productos Sanitarios (AEMPS) la que indicará si un producto es considerado como cosmético según sus características y de conformidad con las definiciones del Reglamento (CE) núm. 1223/2009.

\section{Seguridad, trazabilidad, envasado y consumidores}

El derecho subjetivo a la salud y seguridad por parte de consumidores y usuarios se plasma en el artículo 51 del texto constitucional (Reyes, 1991; Reyes, 2004). Según la definición del RDL 1/2007 se consideran como tales las personas físicas que actúen sin propósito comercial o empresarial, siendo uno de los derechos básicos la protección contra los riesgos que le puedan afectar a la salud o seguridad. Si bien, hay que tener en cuenta que si consideramos que los cosméticos sólo pueden ser utilizados por las personas físicas, lo que es cierto es que el RDL 1/2007, en su artículo 3, referente al «Concepto general de consumidor y usuario» extiende el concepto de consumidor a efectos de la norma a «las personas jurídicas y las entidades sin personalidad jurídica que actúen sin ánimo de lucro en un ámbito ajeno a una actividad comercial o empresarial» y esta extensión del concepto vino tras la Ley 3/2014, a la que nos hemos referido anteriormente.

El Reglamento (CE) núm. 1223/2009 establece que los productos cosméticos que se vayan a comercializar deberán respetar las buenas prácticas de fabricación, y teniendo en cuenta lo indicado en el Real Decreto 944/2010, del 23 de julio, por el que se modifica el Real Decreto 1599/1997, del 17 de octubre, sobre productos cosméticos para adaptarlo al Reglamento (CE) núm. 1272/2008, del Parlamento Europeo y del Consejo, del 16 de diciembre de 2008, sobre clasificación, etiquetado y envasado de sustancias y mezclas (BOE núm. 189, de 5 de agosto de 2010).

Además, respecto a la seguridad, en su artículo 3 deberán ser seguros para la salud humana y deberán tener en cuenta su presentación cumpliendo lo indicado en la Directiva del Consejo de 25 de junio de 1987 relativa a la aproximación de las legislaciones de los Estados miembros sobre los productos de apariencia engañosa que ponen en peligro la salud o la seguridad de los consumidores (87/357/CEE) (DO L 192 del 11 de julio de 1987) el etiquetado, las instrucciones de utilización y eliminación, y cualquier otra información proporcionada por la persona responsable tal y como se indica en el art. 4 del Reglamento. Como precisa Hernández (2013, 7) analizando los artículos 4 y 5 del Reglamento (CE) núm. 1223/2009, la persona designada como responsable garantizará que el producto es conforme a las normas del Reglamento, y garantizará el cum- 
plimiento de las disposiciones sobre salud, seguridad e información al consumidor. Para asegurar la trazabilidad del producto, deberá poder identificar a los distribuidores durante el plazo de tres años a partir de la puesta a disposición del distribuidor del producto. En los supuestos de falta de conformidad de un producto, la persona responsable adoptará las medidas convenientes para que se retire el mismo o para solicitar su devolución al fabricante. En el caso de no adoptar las medidas necesarias, las podrán adoptar las autoridades. Si el producto planteara o pudiera plantear un riesgo grave para la salud, la autoridad competente deberá adoptar todas las medidas para retirar, recuperar o restringir la disponibilidad del producto en el mercado.

El sistema español de cosmetovigilancia deberá funcionar conforme a las normas que dicta el RD 85/2018, siguiendo las directrices del artículo 35.6 del Real Decreto 1275/2011, del 16 de septiembre, por el que se crea la Agencia estatal «Agencia Española de Medicamentos y Productos Sanitarios» (BOE núm. 229, del 23 de septiembre de 2011), que establece que el departamento de productos sanitarios tendrá como función la planificación, desarrollo y gestión de los sistemas de vigilancia de los productos sanitarios y de los cosméticos, que actuarán como centro de referencia en las redes europeas.

Dentro del ámbito de la comercialización del producto, tenemos que tener en cuenta lo indicado en el Reglamento (CE) núm. 765/2008 del Parlamento Europeo y del Consejo de 9 de julio de 2008 por el que se establecen los requisitos de acreditación y vigilancia del mercado relativos a la comercialización de los productos y por el que se deroga el Reglamento (CEE) núm. 339/93 precisa de forma rigurosa los controles que debe de observar el Estado a efectos de introducción en el mercado comunitario los productos (DOUE L 218/30 del 13 de agosto de 2008).

Más recientemente se ha aprobado la Decisión (UE) 2019/701 de la Comisión, de 5 de abril de 2019, por la que se establece un glosario de nombres comunes de ingredientes para su utilización en el etiquetado de los productos cosméticos (DOUE núm. 121, de 8 de mayo de 2019).

También, como indica el RD 85/2018 debe aplicarse lo preceptuado en la Orden SPI/2136/2011, del 19 de julio, por la que se fijan las modalidades de control sanitario en frontera por la inspección farmacéutica y se regula el Sistema Informático de Inspección Farmacéutica de Sanidad Exterior (BOE núm. 181, de 29 de julio de 2011), modificada por Orden SSI/2375/2014, de 11 de diciembre (BOE núm. 306, de 19 de diciembre de 2014) y que según su artículo 2. d) su ámbito de aplicación 
se extiende a los cosméticos y productos de higiene personal, incluyendo sus graneles y productos intermedios. El presente RD 85/2018, en su artículo 5 y siguientes desarrolla los requisitos que se tienen que aplicar por parte de la Inspección Farmacéutica. También se aplica lo indicado en el Reglamento (UE) núm. 608/2013 del Parlamento Europeo y del Consejo, de 12 de junio de 2013, relativo a la vigilancia por parte de las autoridades aduaneras del respeto de los derechos de propiedad intelectual y por el que se deroga el Reglamento (CE) núm. 1383/2003 del Consejo (DOUE núm. 181, de 29 de junio de 2013).

Una de las medidas de seguridad que contempla el RD 85/2018 es el etiquetado de los productos cosméticos. Se establece que figure en español (aunque se podrá aceptar documentación científica especializada en francés o inglés) la información que se indica en el artículo 11 y 19, 2, 3 y 4 del Reglamento (CE) núm. 1223/2009.

Por lo que se refiere a los productos cosméticos que se comercialicen en España y que presenten un riesgo para la salud de las personas, se contempla un protocolo de comunicación y transmisión de los riesgos y efectos graves no deseados en el artículo 8 RD 85/2018. Serán o bien la persona responsable o el distribuidor quien deberá informar a la AEMPS y le indicará las medidas correctoras adoptadas que se contemplan en los arts. 5 y 6 del Reglamento (CE) núm. 1223/2009.

La comunicación de los riesgos se realizará según indica el artículo 19 del Real Decreto 1801/2003, de 26 de diciembre, sobre seguridad general de los productos (BOE núm. 9, de 10 de enero de 2004) mediante el sistema estatal de intercambio rápido de información, la red de alerta integrada en el sistema europeo, conocida como RAPEX, con el fin de comunicar e intercambiar la información de manera rápida en las actuaciones que se adopten en los casos en que haya un riesgo de carácter grave.

Los responsables y distribuidores deberán notificar en los casos de efectos graves no deseados que se produzcan en territorio español a la AEMPS tanto los indicados efectos, como el nombre del producto cosmético, y las medidas correctoras adoptadas.

En el caso de que tengan conocimiento de efectos graves no deseados los profesionales sanitarios entre los que se incluyen tanto médicos, farmacéuticos, enfermeros, entre otros, deberán notificarlo a la autoridad sanitaria autonómica, y si actúan como distribuidores de esos productos deberán notificarlo a la AEMPS. 
Se regulan en el artículo 12 y siguientes del RD 85/2018 medidas de control para la protección de la salud, entre las que se encuentran el cumplimiento de los principios de buenas prácticas de fabricación. Si hay duda respecto a la seguridad de una sustancia que contenga el producto cosmético, las autoridades competentes que se señalan en el artículo 5 del RD 85/2018 podrán solicitar a la persona responsable que presente un listado de los productos que estén bajo su responsabilidad y que contengan la sustancia, indicando su concentración.

Se contemplan la adopción de medidas cautelares, precautorias, de prevención o protección de la salud en el caso de que se produzca o haya una sospecha de riesgo para la salud en el caso de los productos cosméticos. Estas medidas se contienen en el artículo 109 RDL 1/2015, y son las siguientes: «c) La limitación, prohibición, suspensión o sujeción a condiciones especiales de la fabricación, importación, comercialización, exportación, publicidad, puesta en servicio o utilización de los productos sanitarios, cosméticos o productos de cuidado personal, así como la puesta en cuarentena, la retirada del mercado y la recuperación de dichos productos».

En el caso de incumplimiento, las autoridades competentes podrán exigir a la persona responsable que adopte las medidas consecuentes para que se retire el producto del comercio. También les podrán exigir a los distribuidores estas mismas medidas.

Se regula un sistema de información en red para intercambiar información sobre seguridad de los productos cosméticos. Servirá para la comunicación de la información sobre las medidas que se adopten en los supuestos de riesgos para la salud humana o efectos graves no deseados que se hayan producido por los productos cosméticos. También se informará sobre las recomendaciones o advertencias que fueran oportunas para la protección de la salud y el uso seguro de los productos.

Se contemplan las denominadas buenas prácticas de fabricación de los productos. Será competencia de la AEMPS la supervisión de que el producto ha sido fabricado de conformidad con los principios de buenas prácticas como determinan los arts. 8 y 22 Reglamento (CE) núm. 1223/2009. A petición del interesado, la autoridad actuante podrá expedir un certificado de cumplimiento de los principios de buenas prácticas, en el que se podrá incluir un plazo de validez que no excederá de tres años.

Una de las garantías reguladas en el RD 85/2018 es el sistema español de cosmetovigilancia. Se trata de una actividad que se destina a la recogida, evaluación y seguimiento de la información sobre los efectos no deseados observados como con- 
secuencia del uso normal o previsto de los productos cosméticos (artículo 16 RD 85/2018).

Está coordinado por la AEMPS y comprende las actividades de dicha agencia, la de las autoridades sanitarias autonómicas, y los profesionales de sanidad, así como también la participación de consumidores y profesionales que utilizan o aplican los productos cosméticos, en la notificación, recogida, evaluación y seguimiento de los efectos no deseados producidos por los cosméticos, así como la adopción de las medidas y difusión de la información (Cfr. artículo 16.3, 4 y 5 RD 85/2018).

\section{Ámbito de responsabilidad y su aplicación en el caso de productos defectuosos}

Cuestión importante es la delimitación de la responsabilidad en el caso de los productos cosméticos, ya que entran en juego determinadas figuras como el productor, distribuidor, importador, vendedor, además de personas físicas, también personas jurídicas. La doctrina también se ha ocupado de estudiar que el producto cosmético debe ser sometido a evaluaciones toxicológicos (Cfr. Altunaga, García, Paz y Vegas, 2000; Altunaga, García, Valdivieso, D’Lama, Piloto y Figueredo, 2000; Balaguer, 2008; Carballal, Yip, Altunaga, Moure, Leyva, Torres y Figueredo, 2011; Lapuente, Borrás, González, Llanas, Ramos y Vinardell, 2014) para que el producto sea lo más seguro posible y no provoque daños al consumidor (Bueno, 2005).

Los productos cosméticos se diferencian de otros sectores como es el alimentario, farmacéutico, y el término «evaluación del riesgo» se sustituye por el de «evaluación de la seguridad», ya que debe ser el producto seguro a priori (Álvarez, 2004).

El Reglamento (CE) núm. 1223/2009 establece la obligación de informar sobre los efectos graves no deseados a las autoridades del país por parte de los responsables de los productos cosméticos y por los distribuidores.

En el artículo 17 RD 85/2018 se contemplan los requisitos que deben cumplir las personas físicas o jurídicas que realicen actividades de fabricación e importación de productos cosméticas, que se contienen en el anexo del RD 85/2018.

Importante destacar el desarrollo del procedimiento de declaración responsable de actividades de fabricación e importación que mencionaba el RDL 1/2015, y que 
se considera como infracción grave en el artículo 113, en materia de productos cosméticos la fabricación o importación de productos cosméticos, o trasladar, ampliar o modificar sustancialmente las actividades e instalaciones sin haber presentado la declaración responsable de cumplimiento de los requisitos para realizar dichas actividades, así como fabricar o importar estos productos sin atenerse a las condiciones manifestadas en la declaración responsable, así como elaborar los productos cosméticos sin observar los principios de buenas prácticas de fabricación. De igual modo, tienen también la consideración de infracción grave la introducción en el mercado de productos cosméticos fabricados en instalaciones que no hayan sido objeto de declaración responsable. Y como infracción muy grave, falsear la información que se debe proporcionar a las autoridades sanitarias y falsear la declaración responsable de cumplimiento de los requisitos para la realización de actividades de fabricación e importación.

Además, según lo indicado en la disposición adicional tercera del RDL 1/2015, las actividades referentes a la fabricación e importación de cosméticos se someterán a lo indicado en el artículo 69 de la Ley 39/2015, de 1 de octubre, del Procedimiento Administrativo Común de las Administraciones Públicas (BOE núm. 236, de 2 de octubre de 2015). Dicho precepto establece textualmente:

1. A los efectos de esta Ley, se entenderá por declaración responsable el documento suscrito por un interesado en el que éste manifiesta, bajo su responsabilidad, que cumple con los requisitos establecidos en la normativa vigente para obtener el reconocimiento de un derecho o facultad o para su ejercicio, que dispone de la documentación que así lo acredita, que la pondrá a disposición de la Administración cuando le sea requerida, y que se compromete a mantener el cumplimiento de las anteriores obligaciones durante el período de tiempo inherente a dicho reconocimiento o ejercicio.

Los requisitos a los que se refiere el párrafo anterior deberán estar recogidos de manera expresa, clara y precisa en la correspondiente declaración responsable. Las Administraciones podrán requerir en cualquier momento que se aporte la documentación que acredite el cumplimiento de los mencionados requisitos y el interesado deberá aportarla.

2. A los efectos de esta Ley, se entenderá por comunicación aquel documento mediante el que los interesados ponen en conocimiento de la Administración 
Pública competente sus datos identificativos o cualquier otro dato relevante para el inicio de una actividad o el ejercicio de un derecho.

3. Las declaraciones responsables y las comunicaciones permitirán, el reconocimiento o ejercicio de un derecho o bien el inicio de una actividad, desde el día de su presentación, sin perjuicio de las facultades de comprobación, control e inspección que tengan atribuidas las Administraciones Públicas.

No obstante lo dispuesto en el párrafo anterior, la comunicación podrá presentarse dentro de un plazo posterior al inicio de la actividad cuando la legislación correspondiente lo prevea expresamente.

4. La inexactitud, falsedad u omisión, de carácter esencial, de cualquier dato o información que se incorpore a una declaración responsable o a una comunicación, o la no presentación ante la Administración competente de la declaración responsable, la documentación que sea en su caso requerida para acreditar el cumplimiento de lo declarado, o la comunicación, determinará la imposibilidad de continuar con el ejercicio del derecho o actividad afectada desde el momento en que se tenga constancia de tales hechos, sin perjuicio de las responsabilidades penales, civiles o administrativas a que hubiera lugar.

Asimismo, la resolución de la Administración Pública que declare tales circunstancias podrá determinar la obligación del interesado de restituir la situación jurídica al momento previo al reconocimiento o al ejercicio del derecho o al inicio de la actividad correspondiente, así como la imposibilidad de instar un nuevo procedimiento con el mismo objeto durante un período de tiempo determinado por la ley, todo ello conforme a los términos establecidos en las normas sectoriales de aplicación.

5. Las Administraciones Públicas tendrán permanentemente publicados y actualizados modelos de declaración responsable y de comunicación, fácilmente accesibles a los interesados.

6. Únicamente será exigible, bien una declaración responsable, bien una comunicación para iniciar una misma actividad u obtener el reconocimiento de un mismo derecho o facultad para su ejercicio, sin que sea posible la exigencia de ambas acumulativamente. 
Posteriormente serán comprobadas las actividades por la Agencia Española de Medicamentos y Productos Sanitarios.

La declaración responsable anteriormente referida y que se contiene en el artículo 18 RD 85/2018 deberá contener los datos del titular de la actividad, de la persona cualificada de contacto, de las instalaciones, categorías y formas cosméticas y fecha prevista del inicio de las actividades.

Por su parte, el titular de la actividad deberá indicar que cumple con los requisitos y obligaciones que le sean inherentes para el ejercicio de fabricación e importación que se indican de forma expresa en el anexo del RD 85/2018; que dispone de la documentación que lo acredite; y que se compromete a cumplir con los requisitos indicados.

Respecto a las oficinas de farmacia que elaboren productos cosméticos para venderlos en la misma (Aliaga, 2004) el artículo 26 RD 85/2018 indica de forma expresa la aplicación de lo dispuesto en el artículo 18.3 c) que exonera de la declaración responsable a las oficinas de farmacia que elaboren productos cosméticos exclusivamente para su venta en la misma, pero sí que deberán cumplir los requisitos del anexo referentes a la fabricación de los productos cosméticos.

En el anexo del RD 85/2018 se establecen los requisitos para realizar actividades de fabricación y que, brevemente, son los siguientes: disponer de un sistema de calidad actualizado que establezca las responsabilidades y que garanticen que la fabricación de los productos se realice de acuerdo con los principios de buenas prácticas [artículo 8.1 Reglamento (CE) núm. 1223/2009]; disponer de estructura organizativa; disponer de personal cualificado; disponer de programas de formación en buenas prácticas; disponer de instalaciones y equipos. Las instalaciones deberán contar con áreas para fabricación y almacenamiento; disponer de instalaciones, equipos, reactivos y patrones suficientes para las actividades de control y garantía de la calidad de los materiales utilizados; disponer de procedimientos escritos de trabajo que describan las actividades (compra, recepción, liberación, almacenamiento, realización de operaciones de fabricación y acondicionado, liberación y control, almacenamiento y expedición de productos, revisión e investigación de reclamaciones, realización de auditorías internas, archivo de documentación, ejecución de acciones para la retirada de productos del mercado, registros de verificación de las actividades, contratos para actividades subcontratadas). 
Respecto a la responsabilidad, se establece que los titulares de las oficinas de farmacia asumirán las obligaciones que les correspondan a las personas responsables en el Reglamento (CE) núm. 1223/2009 referentes a la comunicación de efectos graves no deseados y de riesgos para la salud humana. Se podrá designar como persona responsable a una persona establecida en la Unión Europea, que debe aceptar por escrito.

Llegado a este punto, debemos hacer apreciación de varias consideraciones respecto a la responsabilidad. Considerada como la obligación de reparación del daño y partiendo del concepto amplio de persona (Hernández, 2013, p. 6), la responsabilidad se puede enfocar durante la relación fabricante-distribuidor-consumidor, bien por disconformidad con el producto o bien porque el producto es defectuoso.

El artículo 27 RD 85/2018 determina que los establecimientos que fraccionen para venta al público productos cosméticos a granel destinados por el fabricante a dicho fraccionamiento, como pueden ser colonias y jabones sólidos, deberán atender a las instrucciones del fabricante. Tendrán, a efectos de responsabilidad, la consideración de fabricantes o distribuidores y asumirán todas las obligaciones que les indique el Reglamento (CE) núm. 1223/2009, y estarán sujetos a la supervisión de las autoridades sanitarias autonómicas.

Centrándonos en el caso del producto defectuoso, ni el Reglamento (CE) núm. 1223/2009, ni el RD 85/2018 mencionan el defecto del producto. Debemos acudir a la responsabilidad por daños extracontractuales principalmente el Reglamento (CE) núm. 864/2007 del Parlamento Europeo y del Consejo de 11 de julio de 2007 relativo a la ley aplicable a las obligaciones extracontractuales («Roma II») (DOUE L 199/40 del 31 de julio de 2007). Según su artículo 2 entiende por daños todas las consecuencias resultantes de un hecho dañoso, el enriquecimiento injusto, la gestión de negocios o la culpa in contrahendo. El daño incluirá cualquier daño que se pueda producir. Se aplicará también lo indicado en el artículo 5 que regula la responsabilidad por daños causados por productos defectuosos.

En la legislación española, se reguló en sus inicios los daños causados por productos defectuosos por la Ley 22/1994, de 6 de julio, de responsabilidad civil( BOE núm. 161, de 7 de julio de 1994), que quedó derogada por lo indicado en el RDL 1/2007, y que se dicta al amparo de lo indicado en la disposición final quinta de la Ley 44/2006, del 29 de diciembre, de mejora de la protección de los consumidores y usuarios (BOE núm. 312, del 30 de diciembre de 2006). 
Esta norma contiene una regulación que consideramos aplicable a los productos cosméticos, y que se contemplan en los artículos 135 y siguientes. Los productores (a los efectos de los artículos 5 y 138) serán responsables de los daños causados por los defectos de los productos (entendido como cualquier bien mueble) que fabriquen o importen (Reyes, 2002b, 485; Reyes, 2002c, 519).

Como advierte Hernández (2013, 9), «La literalidad de los artículos 132 y siguientes del RDL 1/2007 nos facultan para afirmar y someter la relación fabricantedistribuidor en el sector cosmético bajo el prisma de la responsabilidad solidaria, es decir, si el perjudicado prueba que ha existido el defecto, el daño y la relación de causalidad entre ambos», según el artículo 132, «las personas responsables del mismo daño por aplicación de este libro lo serán solidariamente ante los perjudicados. El que hubiera respondido ante el perjudicado tendrá derecho a repetir frente a los otros responsables, según su participación en la causación del daño».

Así, el artículo 5 indica que se considera productor al fabricante del bien o prestador del servicio o intermediario, o al importador del bien o servicio en el territorio de la Unión Europea, así como a cualquier persona que se presente como tal al indicar en el bien, bien en el envase, envoltorio o cualquier otro elemento de protección o presentación, o servicio su nombre, marca u otro signo distintivo.

En el artículo 138 se considera como productor al fabricante o importador en la Unión Europea de un producto terminado; cualquier elemento integrado en el mismo, o una materia prima.

Se considera que un producto es defectuoso (artículo 137) cuando no ofrezca la seguridad que legítimamente cabría esperar, teniendo en cuenta las circunstancias, su presentación, uso previsible y el momento de su puesta a disposición. En todo caso, se considera defectuoso si no ofrece la seguridad que normalmente ofrecen los demás ejemplares de la misma serie. Defectuoso no es el producto que sea inferior al que posteriormente se perfeccione.

Según el artículo 140 el productor no será responsable en el caso de que pruebe que no había puesto en circulación el producto, o que es posible la presunción de que el defecto del mismo no existía en el momento en que se puso en circulación, o bien que el producto no había sido fabricado para la venta o distribución con finalidad económica, ni fabricado, importado, suministrado o distribuido en el marco de una actividad económica, o bien que el defecto se debió a que el producto se había 
elaborado de conformidad a las normas imperativas existentes, o que el estado de los conocimientos científicos y técnicos existentes cuando se puso en circulación, no permitieron apreciar que estaba defectuoso.

Por lo que se contempla de la responsabilidad del proveedor, el artículo 146 señala que responderá en los mismos términos del productor, en el caso de que haya suministrado el producto sabiendo de la existencia de su defecto. Se establece que el proveedor pueda ejercitar una acción de repetición contra el productor.

En la disposición transitoria tercera se indica la aplicación del régimen de responsabilidad que contempla el artículo 148 (régimen especial de responsabilidad originado por los daños en el correcto uso de los servicios cuando incluyan garantías de eficacia o seguridad) a los productos cosméticos defectuosos que hayan sido puestos en circulación antes del 8 de julio de 1994.

Por último debemos apuntar lo que se indicaba en la Directiva 2003/15/CE del Parlamento Europeo y del Consejo del 27 de febrero de 2003 por la que se modifica la Directiva 76/768/CEE del Consejo relativa a la aproximación de las legislaciones de los Estados miembros que se expresan respecto del riesgo en materia de productos cosméticos (L 66/26 DOUE del 11 de marzo de 2003) se expresa respecto del riesgo al consumidor y la fecha de apertura del producto, lo que se denomina PAO (period after opening) (Alcalde, 2004), que las indicaciones sobre la fecha de duración mínima no es obligatoria para los productos cosméticos cuya vida mínima exceda de 30 meses (Romero y Pozo, 2004). En estos casos se indicará el plazo después de la apertura durante el que los productos se pueden utilizar sin riesgo para el consumidor (Viscasillas, Juvé y Pozo, 2005; Aliaga, 2006).

\section{Conclusiones}

El consumo de productos cosméticos se ha incrementado considerablemente (Sandbiller y Valor, 2011). El consumidor tiene en cuenta factores que influyen en su comportamiento, algunos psicológicos (Garcillán, 2014) y otros tan peregrinos como el envasado (Valle y Jiménez, 2014), la apariencia del producto, su textura, y, cómo no, se rige por la publicidad que se haya realizado del producto (Radu y Oprescu, 2009; Pellicer, 2016a, 111; Pellicer, 2016b, 224), y que, en algunas ocasiones, le puede provocar confusión (Clemente, Escribá y Buitrago, 2014). 
La venta de estos productos en supermercados, perfumerías, o farmacias no debe ser distinta respecto a lo que se refiere a seguridad del mismo para el consumidor (Echarte, 2009). Deben ser seguros y cumplir las normas de calidad, ya se vendan en un sitio u otro. Es verdad que en alguna ocasión hemos observado que el consumidor indique que si un cosmético se vende en una farmacia es de mejor calidad, o más seguro, que el que se venda en una cadena de supermercados. Pero la realidad no es así.

Los mecanismos de control deben de ser observados según la legislación aplicable, teniendo en cuenta las competencias autonómicas en la materia (González, 1995). Los productos cosméticos tienen que ser evaluados según diferentes técnicas para determinar la inocuidad de los mismos (Trullas y Coll, 2000).

El RD 85/2018 que hemos analizado en el presente trabajo incide en aspectos tan importantes como la trazabilidad de los productos cosméticos, así como el cumplimiento de los principios de buenas prácticas. Se atiende durante todo el texto legal a lo indicado en el Reglamento (CE) núm. 1223/2009.

Los elementos que incorpora el RD 85/2018 para aplicarse en nuestro ordenamiento jurídico participan de cuestiones relativas a la supervisión y la notificación sobre los efectos graves para la salud, así como la adopción de medidas precautorias y de protección.

Consideramos que respecto a la responsabilidad y la protección de los consumidores (Reyes, 2013), en especial en el caso de los productos cosméticos, deben aplicarse las normas de responsabilidad civil que se contienen en el ámbito civil, ya que el RD 85/2018 resulta insuficiente. Los derechos de los consumidores, como el derecho a la salud, están relacionados con la seguridad de los productos (Reyes, 2002a). 


\section{Referencias}

Alcalde Pérez, M. T. (2004). Productos cosméticos: cómo leer su etiqueta. Offarm: farmacia y sociedad, 23(8), 108-115. Recuperado de https://es.scribd.com/ document/161271117/Productos-cosmeticos-como-leer-su-etiqueta

Aliaga Pérez, A. (2004). Elaboración de productos cosméticos en la oficina de farmacia. Farmacéuticos: Revista del Colegio General de Oficiales de Farmacéuticos, 284, 28-31.

Aliaga Pérez, A. (2006). Etiquetado de productos cosméticos. Farmacéuticos: Revista del Colegio General de Oficiales de Farmacéuticos, 308, 54-57.

Altunaga Cantero, L., García Simón, G., Paz Luna, M. De La, Figuereo Castro, N. y Vegas Montalvo, R. (2000). Utilización del método alternativo HET-CAM en la evaluación toxicológica de productos cosméticos y materias primas. Alimentaria: Revista de tecnología e higiene de los alimentos, 317, 161-166.

Altunaga Cantero, L., García Simón, G., Valdivieso García, A., D’Lama Fuentes, D., Piloto Alfonso, A. y Figueredo Castro, N. (2000). Ensayos toxicológicos alternativos realizados a productos cosméticos. Alimentaria: Revista de tecnología e higiene de los alimentos, 312, 29-32.

Álvarez Rivera, G. (2015). Desarrollo y aplicación de nuevas herramientas (bio) analíticas para el control de la seguridad de los productos cosméticos y de cuidado personal, Tesis doctoral dirigida por Marta Lores Aguín y María Pilar Llompart Vizoso. Santiago de Compostela: Universidade de Santiago de Compostela. Recuperado de https://minerva.usc.es/xmlui/handle/10347/13566

Balaguer Timor, A. (2008). Desarrollo de métodos analíticos para la estimación de la seguridad y el control de calidad de los productos cosméticos, Tesis doctoral dirigida por Alberto Chisvert Sania y Amparo Salvador Carreño. Valencia: Universitat de València. Recuperado de http://roderic.uv.es/bitstream/handle/ 10550/14948/balaguer.pdf?sequence=1\&isAllowed=y

Camps, M. (2006). La legislación de cosméticos hoy. Industria farmacéutica: Equipos, procesos y tecnología, 128, 29-33. 
Carballal, M., Yip Aramillo, J., Altunaga Cantero, L., Moure, M., Leyva Castillo, V., Torres Schery, S., García, I. y Figueredo Castro, N. (2011). Aplicación de análisis de riesgo y puntos críticos y de control en productos cosméticos y artículos de aseo y limpieza. Alimentaria: Revista de tecnología e higiene de los alimentos, 328, 107-112.

Clemente Ricolfe, J. S., Escribá Pérez, C. y Buitrago Vera, J. M. (2014). Respuestas ante la confusión del consumidor por información ambigua: el caso de los cosméticos de una cadena de supermercados en España. Aposta: Revista de Ciencias Sociales, 62, 1-25. Recuperado de http://www.apostadigital.com/ revistav3/hemeroteca/carespe.pdf

Echarte Alonso, L. E. (2009). Psicofarmacología terapéutica y cosmética: riesgos y límites. Cuaderns de bioética, Asociación Española de Bioética y Ética, 20(69), 211-230. Recuperado de http://aebioetica.org/revistas/2009/20/2/69/ 211.pdf

Fernández Rodríguez, M. C., Fresno Contreras, Ma . J. y Sellés Flores, E. (1995). Legislación farmacéutica: autorización de cosméticos. Farmacia profesional, 9(5), 57-67.

Garcillán López-Rúa, M. De (2014). La psicología del consumidor a la hora de comprar un producto cosmético. Revista de análisis transaccional y psicología humanista, Asociación española de análisis transaccional, 71, 589600. Recuperado de http://com.aespat.es/Revista/Revista_ATyPH_71.pdf

Garrigues (2018). La nueva regulación sobre productos cosméticos aumenta su seguridad y facilita su comercialización. Recuperado de http://www.garrigues. com/es_ES/noticia/la-nueva-regulacion-sobre-productos-cosmeticos-aumentasu-seguridad-y-facilita-su

González Bueno, A. (1995). Crónica legal del medicamento: los productos cosméticos bajo el control de las Comunidades Autónomas. Acofar: Revista de la distribución farmacéutica cooperativista, 337, 29-30.

González Bueno, A. (2005). Cosméticos más seguros y con más información, Acofar: Revista de la distribución farmacéutica cooperativista, 441, 22-26. 
Hernández Fernández, A. (2013). La cara oculta de la distribución en el sector de la cosmética: Responsabilidad y encroachment. 3c Empresa: investigación y pensamiento crítico, 2(2), 1-17. Recuperado de http://ojs.3ciencias.com/ index.php/3c-empresa/article/view/145

Lapuente, J. De, Borrás Suárez, M., González Linares, J., Llanas, H., Mitjans, M., Ramos López, D. y Vinardell, M. P., (2014). Los métodos alternativos en el estudio de la seguridad de cosméticos. Revista de toxicología, 31(2), 140-148. Recuperado de http://www.redalyc.org/articulo.oa?id=91932969012

López Cantos, F. (2016). Envejecimiento, ciencia y publicidad de cosméticos. La eternidad en una gota de crema. Vivat Academia, 135, 41-56. Recuperado de http://repositori.uji.es/xmlui/handle/10234/162181

Martín Barea, M. P. (1998). Legislación sobre productos cosméticos. Offarm: farmacia y sociedad, 17(6), 94-104.

Pellicer Jordá, Ma . T. (2016a). La publicidad de los cosméticos y los códigos éticos: estudio de caso. Hologramática, 2(25), 111-135. Recuperado de http://www.cienciared.com.ar/ra/revista.php?wid=3\&articulo=2009\&tipo=\&ei $\mathrm{d}=26 \&$ sid $=136 \&$ NombreSeccion=Articulos $\&$ Accion=Completo

Pellicer Jordá, $M^{\mathrm{a}}$. T. (2016b). La publicidad de los cosméticos: ¿cumple los códigos éticos? Etic@net, 1(16), 224-239. Recuperado de http://eticanet.org/revista/ index.php/eticanet/article/view/102/93

Prats, L. (2013). Entra en vigor el Reglamento europeo de productos cosméticos. Infopack: packaging \& etiquetaje industrial, diseño, innovación \& tendencias, 192, 16.

Radu Lefebvre, M. y Oprescu, M. (2009). En busca de la belleza entre espejismo(s) y eficacia(s). El impacto de la publicidad para productos cosméticos adelgazantes. El rol moderador de las estrategias de comparación social. Revista Comunicación y Medios, 19, 85-98. Recuperado de https://revista literatura.uchile.cl/index.php/RCM/article/view/11097/11400 
Reyes López, Ma. J. (1991). Derechos básicos de los consumidores y usuarios reconocidos en la legislación vigente, en especial el derecho a la protección de la salud y seguridad; el derecho a la información y a la educación; el derecho a la representación y audiencia en consulta. Revista general de Derecho, 564, 7079-7097.

Reyes López, Ma. J. (2002a). La protección del derecho básico a la salud y a la seguridad de los consumidores. En: María José Reyes López (coord.). Derecho de Consumo, (121-142). Valencia: Tirant lo Blanch.

Reyes López, Ma . J. (2002b). El régimen general de responsabilidad civil protector de los derechos de los consumidores y usuarios. En M. J. Reyes López (coord.). Derecho de Consumo, (485-502). Valencia: Tirant lo Blanch.

Reyes López, Mª. J. (2002c). La responsabilidad civil por los daños causados por productos defectuosos. En M. J. Reyes López (coord.). Derecho de Consumo, (519-530). Valencia: Tirant lo Blanch.

Reyes López, Ma. J. (2004). La protección de los derechos de los consumidores y usuarios. En M. J. Reyes López (coord.). Derecho Privado de consumo, (1944). Valencia: Tirant lo Blanch.

Reyes López, Mª J. (2013). La protección de los consumidores y la transformación del derecho privado en la Unión Europea. En: David Ordóñez Solis (coord.). La recepción del derecho de la Unión Europea en España: derechos, mercado único y armonización fiscal en Europa: Liber Amicorum en homenaje a Antonio Martínez Lafuente, (347-367). Madrid: La Ley.

Romero, M. C. y Pozo, A. Del (2004). Directiva 2003/15/CEE sobre productos cosméticos. Offarm: farmacia y sociedad, 23(6), 146-148. Recuperado de http://www.elsevier.es/es-revista-offarm-4-articulo-directiva-2003-15-ceesobre-productos-cosmeticos-13064001

Ruiz Cairó, E. (2015). Le nouveau Règlement n 1223/2009 des produits cosmétiques: la recherche d'un équilibre entre innovation et protection des consommateurs. Revista de Derecho Europeo, 53, 113-148. 
Sandbiller, S. y Valor Martínez, C. (2011). Consumo responsable de productos cosméticos: la respuesta del sector en el canal minorista masivo. Distribución y consumo,. 115, 40-55. Recuperado de http://www.mercasa.es/files/ multimedios/1298393625_pag_040-055_Sandbiller.pdf

Trullàs, C. y Coll, J. (2000). Evaluación de la inocuidad de productos cosméticos mediante técnicas biofísicas no invasivas. Acofar: Revista de la distribución farmacéutica cooperativista, 384, 40-44.

Valle, L. y Jiménez, A. (2014). Cómo garantizar la seguridad en el envasado alimentario y cosmético. Infopack: packaging \& etiquetaje industrial, diseño, innovación \& tendencias, 200, 20-25.

Viscasillas, A., Juvé, J. y Pozo, A. Del (2005). Etiquetados de productos cosméticos. Séptima modificación de la Directiva Europea. Offarm: farmacia y sociedad, 24(4), 156-157. Recuperado de http://www.elsevier.es/pt-revista-offarm-4articulo-etiquetado-productos-cosmeticos-septima-modificacion-13073457

\section{Anexo 1. Modificaciones del RDL 1/2007}

—Ley 25/2009, de 22 de diciembre, de modificación de diversas leyes para su adaptación a la Ley sobre el libre acceso a las actividades de servicios y su ejercicio (BOE núm. 308, del 23 de diciembre de 2009), cuyo artículo 4 añade dos nuevos apartados al artículo 21, sobre el «Régimen de comprobación y servicios de atención al cliente», se añade al artículo 49.1, relativo a «Infracciones en materia de defensa de los consumidores y usuarios» una nueva letra $\mathrm{k}$ ), pasando el actual contenido de ésta a la letra l), y se añade al artículo 60.2, que trata sobre «Información previa al contrato», una nueva letra h).

—Ley 29/2009, de 30 de diciembre, por la que se modifica el régimen legal de la competencia desleal y de la publicidad para la mejora de la protección de los consumidores y usuarios (BOE núm. 315, de 31 de diciembre de 2009), en su art. 3.7. modifica el artículo 123, referente a los «Plazos», de tal forma que se le adiciona un nuevo apartado, el tercero, y pasan los apartados 3 y 4 anteriores a numerarse como 4 y 5.

—Ley 15/2015, de 2 de julio, de la Jurisdicción Voluntaria (BOE núm. 158, de 3 de julio de 2015), modifica su disposición final 17.1 el artículo 19, relativo a «Principio 
general y prácticas comerciales», y también modifica el artículo 141, en su letra a), respecto al «Límite de responsabilidad».

- Ley 7/2017, de 2 de noviembre, por la que se incorpora al ordenamiento jurídico español la Directiva 2013/11/UE, del Parlamento Europeo y del Consejo, de 21 de mayo de 2013, relativa a la resolución alternativa de litigios en materia de consumo (BOE núm. 268, de 4 de noviembre de 2017), cuya disposición final 5 modifica los apartados 3 y 4 del artículo 21, que regula el «Régimen de comprobación y servicios de atención al cliente».

-Real Decreto-ley 9/2017, de 26 de mayo, por el que se transponen directivas de la Unión Europea en los ámbitos financiero, mercantil y sanitario, y sobre el desplazamiento de trabajadores (BOE núm. 126, de 27 de mayo de 2017), la disposición final 1 modifica el apartado 3 del artículo 66 bis relativo a la «Entrega de los bienes comprados mediante un contrato de venta», y también afecta al apartado 1 del artículo 107 que trata de los «Derechos y obligaciones del empresario en caso de desistimiento».

—Ley 4/2018, de 11 de junio, por la que se modifica el texto refundido de la Ley General para la Defensa de los Consumidores y Usuarios y otras leyes complementarias, aprobado por Real Decreto Legislativo 1/2007, de 16 de noviembre (BOE núm. 142, de 12 de junio de 2018), incluye, en su artículo único, una disposición adicional única, referente a «Nulidad de determinadas cláusulas» y añade una nueva disposición final cuarta que sobre «Ampliación a otras enfermedades».

—Real Decreto-ley 23/2018, de 21 de diciembre, de transposición de directivas en materia de marcas, transporte ferroviario y viajes combinados y servicios de viaje vinculados (BOE núm. 312, de 27 de diciembre de 2018), cuyo artículo 4 modificó el Libro Cuarto sobre «Viajes combinados y servicios de viaje vinculado», y también modifica el artículo 93, letra g), en lo referente a las «Excepciones».

- Ley 5/2019, de 15 de marzo, reguladora de los contratos de crédito inmobiliario (BOE núm. 65, de 16 de marzo de 2019), cuya disposición final octava añade un nuevo párrafo al artículo 83, sobre la «Nulidad de las cláusulas abusivas y subsistencia del contrato». 


\section{Anexo 2. Modificaciones del Reglamento (CE) núm. 1223/2009}

—Decisión de Ejecución de la Comisión, de 25 de noviembre de 2013, sobre las directrices relativas al anexo I del Reglamento (CE) núm. 1223/2009 del Parlamento Europeo y del Consejo sobre los productos cosméticos (DOUE núm. 315, del 26 de noviembre de 2013);

—Reglamento (UE) núm. 344/2013 de la Comisión, de 4 de abril de 2013, por el que se modifican los anexos I, III, V y VI del Reglamento (CE) núm. 1223/2009 del Parlamento Europeo y del Consejo, sobre los productos cosméticos (DOUE núm. 114, del 25 de abril de 2013);

—Reglamento (UE) núm. 483/2013 de la Comisión, del 24 de mayo de 2013, por el que se modifica el anexo III del Reglamento (CE) núm. 1223/2009 del Parlamento Europeo y del Consejo sobre los productos cosméticos (DOUE núm. 139, del 25 de mayo de 2013);

—Reglamento (UE) núm. 655/2013 de la Comisión, de 10 de julio de 2013, por el que se establecen los criterios comunes a los que deben responder las reivindicaciones relativas a los productos cosméticos (DOUE núm. 190, de 11 del julio de 2013);

—Reglamento (UE) núm. 658/2013 de la Comisión, del 10 de julio de 2013, por el que se modifican los anexos II y III del Reglamento (CE) núm. 1223/2009 del Parlamento Europeo y del Consejo, sobre los productos cosméticos (DOUE núm. 190, del 11 de julio de 2013);

—Reglamento (UE) núm. 1197/2013 de la Comisión, del 25 de noviembre de 2013, por el que se modifica el anexo III del Reglamento (CE) núm. 1223/2009 del Parlamento Europeo y del Consejo sobre los productos cosméticos (DOUE núm. 315, del 26 de noviembre de 2013);

—Reglamento (UE) núm. 358/2014 de la Comisión, del 9 de abril de 2014, que modifica los anexos II y V del Reglamento (CE) núm. 1223/2009 del Parlamento Europeo y del Consejo, sobre los productos cosméticos (DOUE núm. 107, del 10 de abril de 2014);

—Reglamento (UE) núm. 866/2014 de la Comisión, del 8 de agosto de 2014, por el que se modifican los anexos III, V y VI del Reglamento (CE) núm. 1223/2009 del 
Parlamento Europeo y del Consejo, sobre los productos cosméticos (DOUE núm. 238, del 9 de agosto de 2014);

—Reglamento (UE) núm. 1003/2014 de la Comisión, del 18 de septiembre de 2014, por el que se modifica el anexo V del Reglamento (CE) núm. 1223/2009 del Parlamento Europeo y del Consejo, sobre los productos cosméticos (DOUE núm. 282, del 26 de septiembre de 2014);

—Reglamento (UE) núm. 1004/2014 de la Comisión, del 18 de septiembre de 2014, por el que se modifica el anexo V del Reglamento (CE) núm. 1223/2009 del Parlamento Europeo y del Consejo, sobre los productos cosméticos (DOUE núm. 282, del 26 de septiembre de 2014);

—Reglamento (UE) 2015/1190 de la Comisión, de 20 de julio de 2015, por el que se modifica el anexo III del Reglamento (CE) núm. 1223/2009 del Parlamento Europeo y del Consejo, sobre los productos cosméticos (DOUE núm. 193, del 21 de julio de 2015);

—Reglamento (UE) 2015/1298 de la Comisión, de 28 de julio de 2015, por el que se modifican los anexos II y VI del Reglamento (CE) núm. 1223/2009 del Parlamento Europeo y del Consejo, sobre los productos cosméticos (DOUE núm. 199, del 29 de julio de 2015);

—Reglamento (UE) 2016/314 de la Comisión, de 4 de marzo de 2016, por el que se modifica el anexo III del Reglamento (CE) núm. 1223/2009 del Parlamento Europeo y del Consejo, sobre los productos cosméticos (DOUE núm. 60, del 5 de marzo de 2016);

—Reglamento (UE) 2016/621 de la Comisión, de 21 de abril de 2016, por el que se modifica el anexo VI del Reglamento (CE) núm. 1223/2009 del Parlamento Europeo y del Consejo, sobre los productos cosméticos (DOUE núm. 106, del 22 de abril de 2016);

—Reglamento (UE) 2016/622 de la Comisión, de 21 de abril de 2016, por el que se modifica el anexo III del Reglamento (CE) núm. 1223/2009 del Parlamento Europeo y del Consejo, sobre los productos cosméticos (DOUE núm. 106, del 22 de abril de 2016); 
—Reglamento (UE) 2016/1120 de la Comisión, de 11 de julio de 2016, por el que se modifica el anexo IV del Reglamento (CE) núm. 1223/2009 del Parlamento Europeo y del Consejo, sobre los productos cosméticos (DOUE núm. 187, del 12 de julio de 2016);

—Reglamento (UE) 2016/1121 de la Comisión, de 11 de julio de 2016, por el que se modifica el anexo V del Reglamento (CE) núm. 1223/2009 del Parlamento Europeo y del Consejo, sobre los productos cosméticos (DOUE núm. 187, del 12 de julio de 2016);

—Reglamento (UE) 2016/1143 de la Comisión, del 13 de julio de 2016, por el que se modifica el anexo VI del Reglamento (CE) núm. 1223/2009 del Parlamento Europeo y del Consejo, sobre los productos cosméticos (DOUE núm. 189, del 14 de julio de 2016), derogado por Reglamento (UE) 2017/706 de la Comisión, del 19 de abril de 2017, que modifica el anexo VII del Reglamento (CE) núm. 1907/2006 del Parlamento Europeo y del Consejo, relativo al registro, la evaluación, la autorización y la restricción de las sustancias y mezclas químicas (REACH), por lo que respecta a la sensibilización cutánea, y que deroga el Reglamento (UE) 2016/1688 de la Comisión (DOUE núm. 104, del 20 de abril de 2017);

—Reglamento (UE) 2016/1198 de la Comisión, de 22 de julio de 2016, por el que se modifica el anexo V del Reglamento (CE) núm. 1223/2009 del Parlamento Europeo y del Consejo, sobre los productos cosméticos (DOUE núm. 198, del 23 de julio de 2016);

—Reglamento (UE) 2017/237 de la Comisión, de 10 de febrero de 2017, por el que se modifica el anexo III del Reglamento (CE) núm. 1223/2009 del Parlamento Europeo y del Consejo sobre los productos cosméticos (DOUE núm. 36, del 11 de febrero de 2017);

—Reglamento (UE) 2017/238 de la Comisión, de 10 de febrero del 2017, por el que se modifica el anexo VI del Reglamento (CE) núm. 1223/2009 del Parlamento Europeo y del Consejo, sobre los productos cosméticos (DOUE núm. 36, del 11 de febrero de 2017);

—Reglamento (UE) 2017/1224 de la Comisión, de 6 de julio de 2017, por el que se modifica el anexo V del Reglamento (CE) núm. 1223/2009 del Parlamento Europeo y del Consejo, sobre los productos cosméticos (DOUE núm. 174, del 7 de julio de 2017);

—Reglamento (UE) 2017/1410 de la Comisión, de 2 de agosto de 2017, por el que se 
modifican los anexos II y III del Reglamento (CE) núm. 1223/2009 del Parlamento Europeo y del Consejo, sobre los productos cosméticos (DOUE núm. 202, del 3 de agosto de 2017);

—Reglamento (UE) 2017/1413 de la Comisión, de 3 de agosto del 2017, por el que se modifica el anexo IV del Reglamento (CE) núm. 1223/2009 del Parlamento Europeo y del Consejo, sobre los productos cosméticos (DOUE núm. 203, del 4 de agosto de 2017);

—Reglamento (UE) 2017/2228 de la Comisión, del 4 de diciembre de 2017, por el que se modifica el anexo III del Reglamento (CE) núm. 1223/2009 del Parlamento Europeo y del Consejo, sobre los productos cosméticos (DOUE núm. 319, de 5 de diciembre de 2017).Corrección de errores del Reglamento (UE) 2017/2228 de la Comisión, de 4 de diciembre de 2017, por el que se modifica el anexo III del Reglamento (CE) núm. 1223/2009 del Parlamento Europeo y del Consejo, sobre los productos cosméticos (DOUE núm. 326, del 9 de diciembre de 2017).

—Reglamento (UE) 2018/1847 de la Comisión, de 26 de noviembre de 2018 por el que se modifica el anexo V del Reglamento (CE) núm. 1223/2009 del Parlamento Europeo y del Consejo, sobre los productos cosméticos (DOUE núm. 300, del 27 de noviembre de 2018).

—Reglamento (UE) 2018/885 de la Comisión, de 20 de junio de 2018, por el que se modifica el anexo VI del Reglamento (CE) núm. 1223/2009 del Parlamento Europeo y del Consejo, sobre los productos cosméticos (DOUE núm. 158, del 21 de junio de 2018).

—Reglamento (UE) 2018/978 de la Comisión, de 9 de julio de 2018, por el que se modifican los anexos II y III del Reglamento CEE 1223/2009. Corrección de errores del Reglamento (UE) 2018/978 de la Comisión, del 9 de julio de 2018, por el que se modifican los anexos II y III del Reglamento (CE) núm. 1223/2009 del Parlamento Europeo y del Consejo sobre los productos cosméticos (DOUE núm. 183, de 19 de julio de 2018).

—Reglamento (UE) 2019/680 de la Comisión, del 30 de abril de 2019, por el que se modifica el anexo VI del Reglamento (CE) núm. 1223/2009 del Parlamento Europeo y del Consejo, sobre los productos cosméticos (DOUE núm. 115, del 2 de mayo de 2019). 
—Reglamento (UE) 2019/681 de la Comisión, de 30 de abril de 2019, pro el que se modifica el anexo II del Reglamento (CE) núm. 1223/2009 del Parlamento Europeo y del Consejo, sobre los productos cosméticos (DOUE núm. 115, del 2 de mayo de 2019).

—Reglamento (UE) 2019/698 de la Comisión, de 30 de abril de 2019, que modifica los anexos III y V del Reglamento (CE) núm. 1223/2009 del Parlamento Europeo y del Consejo, sobre los productos cosméticos (DOUE núm. 119, del 7 de mayo de 2019).

—Reglamento (UE) 2019/831 de la Comisión, de 22 de mayo de 2019, por el que se modifican los anexos II, III y V del Reglamento (CE) núm. 1223/2009 del Parlamento Europeo y del Consejo, sobre los productos cosméticos (DOUE núm. 137, de 23 de mayo de 2019). 